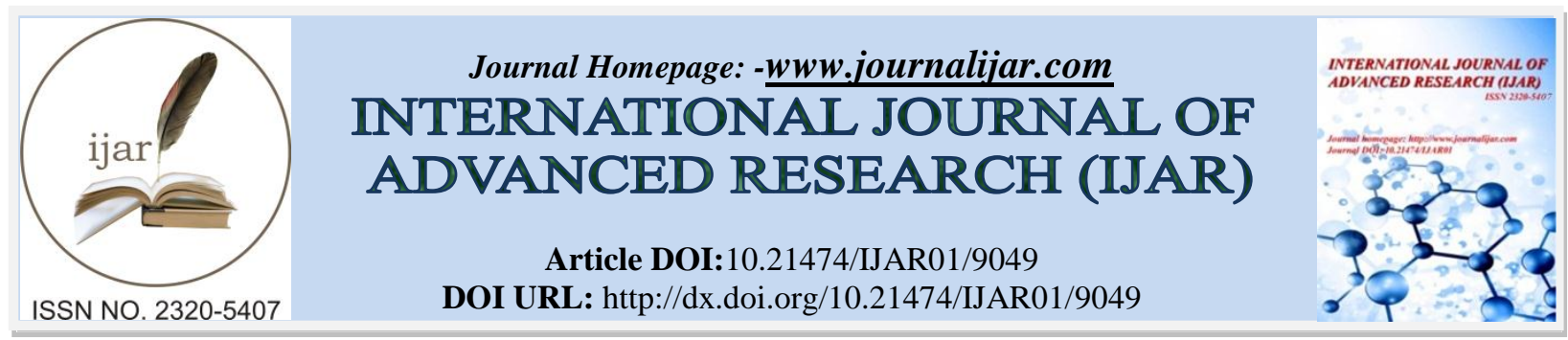

RESEARCH ARTICLE

\title{
ACADEMIC ASSESSMENT SYSTEM OF LEARNERS IN IGNOU.
}

Dr. Pravat Kumar Jena.

Assistant Regional Director, IGNOU Regional Centre, C-1, Institutional Area, Bhubaneswar-751013.

\section{Manuscript Info}

Manuscript History

Received: 12 March 2019

Final Accepted: 14 April 2019

Published: May 2019

\section{Key words:-}

ODL system in India, academic assessment system of IGNOU, assessment strategy, perceptions of learners and academic evaluators.

\begin{abstract}
Distance learning is an excellent method of adult learners to possess the desired higher degree of qualification. Quality of distance education should be maintained properly in order to compete with the present world. Assessment plays a vital role to measure the quality of distance education system. The traditional practice of assessment has changed to meet the need of the modern society. Assessment is no longer used for grading and certification, rather it has linked with learning and skill development of the learners. In India, the Indira Gandhi National Open University (IGNOU) has been providing opportunities of higher education to a large segment of population which is very difficult or impossible by the formal education system. Therefore, a study to analyze the current assessment process of distance education system of IGNOU is needed to highlight strengths and problems in the system. It can be helpful to review the current system to improve its output and establish assessment system on effective basis in future. In this paper, academic assessment strategies used by IGNOU for the learners are discussed. Views/perceptions of the learners and evaluators on the assessment system of IGNOU are analyzed and constructive suggestions are given to meet the challenges of assessment.
\end{abstract}

Copy Right, IJAR, 2019,. All rights reserved.

\section{Introduction:-}

The growing population of India demands a system of education that brings the education to the door steps of the learners with certain flexibility with regard to modalities without compromising necessary quality. The need for such education emerged as the concept of Open and Distance Learning (ODL) system. The ODL system has been established as an effective and innovative alternative system of education in world. It has emerged in the developing countries to promote higher education and play a vital role in accommodating the aspirants, especially adult learners in the higher education sector. This system can fulfill the educational needs of different categories of society such as school/college dropouts, house wives, employed persons who want to learn while earning some livelihood, people from rural areas and all those who are denied access and opportunity for formal education due to geographical distances, socio-economic or cultural barriers.

The Open and Distance Learning formally started in India with the establishment of School of Correspondence Courses in Delhi University during 1962. The success of this experiment inspired the educational planners and policy makers of the country to establish first ever Open University in the State of Andhra Pradesh with the name "Andhra Pradesh Open University" in 1982 (later renamed as Dr Bhim Rao Ambedkar Open University) followed

Corresponding Author:-Dr. Pravat Kumar Jena.

Address:-Assistant Regional Director, IGNOU Regional Centre, C-1, Institutional Area, 
by the establishment of Indira Gandhi National Open University in 1985. As of now, there are 14 state open universities and one national Open University in the country. In addition, about 200 conventional universities recognized as dual mode universities are also running ODL programmes through their directorates of open and distance learning and are substantially contributing to the overall growth of student enrollment in higher education. As per All India Survey on Higher Education (AISHE) 2017-18 (AISHE Report 2018), the present Gross Enrolment Ratio (GER) in higher education is $25.8 \%$ which is calculated for $18-23$ years of age group and distance enrolment constitutes about $11 \%$ of the total enrolment in higher education. It is thought that ODL system is the answer in the developing country like India to raise the GER in higher education and in this context ODL system gains much significance in the present scenario. ODL system of the country consists of IGNOU, State Open Universities (SOUs), Institutions and Universities offering education in dual mode. This is becoming more and more significant for continuing education, skill updation of in service personnel and for quality education of relevance to learners located at educationally disadvantageous locations.

IGNOU practices a flexible and open system of education in regard to methods and place of learning, combination of courses and eligibility for enrolment, age for entry and methods of evaluation etc. The University has adopted an integrated strategy for imparting instruction. This consists of providing print materials, audio-video, tapes, broadcast on radio and educational TV Channels, teleconferencing, video conferencing as also the face to face counselling, at its study centers located throughout the country. The University has adopted the method of continuous assessment and term-end examination for evaluation of the performance of its students enrolled in various subjects. Assessment is not only used for grading and certification, rather it has linked with learning and skill development of the students. Proper assessment can be managed on time by adopting the available IT resources systematically and thoroughly (Mehta and Saxena, 2003). Quality management plays a key role in developing and maintaining quality in distance education institutes. It deals with the quality of the learning experience and the support services. There is a need for innovations that would increase the efficiency and quality of the ODL system (Moumita \& Chinmoy, 2013). Travis (1996) insisted that to be meaningful, the act of assessment must enhance the learning process. To develop confidence in the distance learners, the assessment system should be transparent and as fair as possible so that students never feel frustrated towards the assessment process. To accomplish reliability of the total system of assessment, it should be managed with lesser error and objectivity in scoring (Choudhary \& Dey 2013). Assessment is the most crucial component of the ODL system. The learner in ODL system is generally evaluated through self assessment questions in the course book itself, questions at the end of each unit, multiple choice questions, projects, assignments, and through term end examination. The overall aim of assessment is to ensure that the programme/course results in the expected outcomes from learners.

\section{Objectives of the Study:}

The objective if the study is to:

1. Analyze and understand the learner's academic assessment system of IGNOU.

2. Analyze the views/perceptions of learners and assessors.

3. Suggest workable measures to improve quality of the learner's academic assessment system of IGNOU.

\section{Methodology:-}

Some journals, books and e-contents relating to academic assessment system in distance education are studied to find out the problems associated with assessment system of distance education and its target group. Various methods of academic assessment were discussed and workable solutions for the betterment of academic assessment are suggested. The data on learner's academic assessment system of IGNOU are collected from various research papers, IGNOU profiles and handbooks. The perceptions/views of learners and academic evaluators of IGNOU Regional centre, Bhubaneswar are collected using online Google form and survey method with questionnaires. The collected data are analyzed to study merits and demerits of academic assessment system of IGNOU learners and proposed better methods to make it effective for the learners.

\section{Significance of the Study:}

1. This study highlights the significant features of academic assessment system followed by IGNOU. Therefore, an idea about the strengths and weaknesses of assessment process in distance education programmes can be taken by reviewing the study.

2. The study is most important for researchers who are working on academic assessment system of distance education

3. Results of this study are useful to improve the academic assessment process of distance education programmes. 
4. It may be helpful for planners, organizers of distance education institutions while planning for the improvement of policies on assessment system of distance education.

\section{IGNOU: An Iconic Overview}

IGNOU was established by an act of Parliament in 1985 and has been providing a way of democratising higher education in the country and acts as gateway to the world of Open and Distance Learning. IGNOU being a pioneering ODL institution of higher education and one of the Mega Universities of the world, it has different statutory authorities responsible for different functions and activities. The President of India is the highest authority in his capacity as the Visitor whereas the Vice-Chancellor is the institutional head of the University. The Board of Management is the apex executive body which is responsible for management and administration of the revenue, finances and property as well as conduct of all academic and administrative affairs of the University. The student support services at IGNOU are managed through the Regional Services Division (RSD) with the support of Regional Centers (RCs) and Study Centers (SCs) and individual units execute their own responsibility as per the guidelines of the University. The RCs and SCs provide facilities in terms of general and programme specific information, student enrolment, academic support relating to counselling, assignment evaluation, conducting examinations etc. Academic counselling services of IGNOU is an important activity of learner support services which resolves learners difficulties and generate a good spirit with confidence to achieve the goal (Pravat, 2018). For Evaluation there is Student Evaluation Division (SED) at IGNOU Hqrs., New Delhi and there are six other Regional Evaluation centre(REC)s located at different zones throughout India. All RECs are monitored and controlled by the Registrar, SED. Each REC is allotted with some RCs. During TEE, the examination centers are sending the answer sheets to their respective RECs. RECs do send the answer sheets to different registered evaluators by post or by hand. RECs send the hard copies/softcopies of the award lists to the Registrar SED for declaration of result.

\section{Assessment System of IGNOU:}

Assessment is a process of obtaining information about learners' progress, their achievement in learning and assigning a value to the performance. For example, learner has secured $72 \%$ or an ' $A$ ' grade in an assignment response. The main purpose of assessment is to provide support and feedback to learners to improve their ongoing learning and to report on what they have already achieved. The process of Assessment can be categorized into: formative and summative (STRIDE, IGNOU 2012).

\section{Formative Assessment:}

It is a method to identify the learner's weakness in attaining specific objectives with a view to help the learner to overcome the difficulties.It is used to identify gaps between what students understand and/or skills they possess relative to expected learning objectives for a course and then offer feedback to overcome the weakness before confronting difficult assignments. The formative evaluation practice helps the learner to be self monitoring and self motivating to achieve the goal. Hence, formative assessment is also termed as continuous assessment. It is used frequently throughout the course by providing proper feedback to the learner to evaluate the progress. It can be done using various methods like group discussion, presentation, practice quizzes etc. In distance education system, formative assessment is done through assignments and self assessment questions given in the learning materials.

\section{Summative Assessment:}

It is an assessment which takes place at the end of an activity. In educational system, it is used to assess learners learning, skill acquisition, and academic achievement at the end of an academic session and aims at certifying and grading the attainment of the learners with respect to objectives of a given course. Summative assessment may also be taken into consideration the result of the formative assessment to finalize learners' attainment. It's the more formal summing-up of a learner's progress. It is usually given at the end of the instruction to assess mastery of the learning objectives. In distance education system, both formative and summative assessments are done using a variety of questions: objective, short-answer and long answer type. These are grouped into the following categories: Self-assessment, continuous assessment, and term-end examinations. Besides, some alternative forms of assessment that can be used in distance and online learning situations. Therefore, the following four main categories of academic assessments are used in Distance Education system.

1. Self Assessment

2. Continuous Assessment

3. Term End Examination

4. Alternative Assessment Methods 


\section{Self assessment:}

Self-assessment is a valuable learning tool as well as part of an assessment process. It is a process in which learners can evaluate their own knowledge, track their learning progress, know their weakness, set their goals and revise their works accordingly. This process helps students stay involved and motivated and encourages self-reflection and responsibility for their learning. In IGNOU the Self Assessment is done throughthe Self-Assessment Questions (SAQs) or Check Your Progress (CYP) questions which are spread throughout the Self Learning Material (SLM). This helps the learners to check their progress in developing the relevant knowledge and skills and successful attainment of learning objectives. As there is no teacher to give the feedback to a distance learner just like class room teaching in face-to-face system, the SAQs or CYP given in SLM are the means to provide feedback to the distance learner. These are used as formative evaluation tools to help the learners to learn better. SAQs are mostly the objective type questions and short-answer questions. The self-learning material provides answer/feedback to each of these questions. Learners are expected to use this feedback to compare and self-assess their learning.

\section{Continuous assessment:}

Continuous assessment is the periodic and systematic method of assessing and evaluating a learner's progress. It is an approach which involves the use of a variety of assessment instruments to measure learner's performance and checks various components of learning which are taken place over a period of time. It can replace the final assessment or can be combined with the final assessment to calculate a final grade. In educational system, continuous assessment is a form of educational examination that evaluates a student's progress throughout a prescribed period which is often used as an alternative to the final examination system. In distance education system, Continuous assessment is done through assignments. The main purpose assignment is be to provide regular positive feedback to learners in order to stimulate learning and provide learners with information which will help them judge the effectiveness of their learning strategies. This kind of assessment helps the learners to practice the essential skills such as essay writing, computation, problem solving, drawing, use of scientific apparatus or the operation of equipment without the fear or failure. It is, therefore, essential that the learners should be informed on their performance where it is below expectations or where they have misunderstood assessment tasks.

Assignments used in distance education system are of two types like Computer Marked Assignment (CMA) and Tutor Marked Assignment(TMA) and normally include questions of different types. Some programmes/courses have only TMAs, some have only CMAs and some others have both TMAs and CMAs. These assignments are an essential component of continuous assessment which contributes to the final evaluation of the learners. Submission of these assignments is compulsory for all the learners to take the final examination. The tutor marked assignments are commonly used as a two-way communication tool between the learner and the tutor/teacher. The TMAs rely on long answer; short answer, essay type and problem-solving questions set by the course team or the course writer or the faculty concerned. The student is required to construct his/her own answers. In some courses, learners are required to complete a project or attend an extended contact progamme or workshop which may be equivalent to two or three normal assignments. The distance learners are expected to work on some assignments (usually specified in the Programme Guide) and submit them in their Study Centres. The study centre/programme centre in-charge gets them evaluated by the trained academic counselors appointed for this purpose. The academic counsellors write marginal as well as global teaching comments on these assignments and send them back to the learners in time with feedback on their learning. The assignment responses are evaluated by an academic counsellor, who provides grade/marks and teaching type comments to encourage and motivate the learners. Computer marked assignments (CMAs) consist of objective type questions and the student is asked to select answers from the given alternatives. The student records his/her answers on a special form, Optical Mark Reader (OMR), by marking with pencil through the relevant cell for the question on the forms. The learners are provided feedback on these assignments as well. The computer marked assignments test the students' abilities to recognize or recall certain facts, patterns and information or manipulate specific argument in the course material. Assignments also help the learner to decrease the sense of isolation as a distance learner. The feedback on written assignment is important as it is expected to improve the student performance in the Term End Examination. Normally assignments carry 25-30\% weight in overall assessment. If any learner has not secured pass mark/grade in any assignment, he has to resubmit the fresh assignments. In IGNOU, once the learner has secured pass mark/grade in assignment he/she cannot resubmit for improvement. Assignments are not subject to re-evaluation except for factual errors, if any, on the part of evaluators. Term-End Examination (TEE):

The Term-End Examination (TEE) is the final examination conducted after the end of the duration of a course/programme. It can be organized once or twice in a year depending on institutional policy. The IGNOU 
conducts Term-end Examination twice a year in the month of June and December every year. Students are permitted to appear in Term-end Examination subject to the condition that registration for the courses in which they wish to appear is valid and they have also submitted the required number of assignment(s), if any, in those courses by the due date.Learners are normally given option to decide when and where to appear for the term-end examination. The term-end examinations are mostly pen and paper based. However, alternatives such as practical and project are also used to assess learner performance and are treated as final examination. The term-end examination normally carries about 70-75\% weight in overall assessment. The learners who have completed the programmes of Bachelor's/Master's degree programme but fall short of $2 \%$ marks to secure $2^{\text {nd }}$ and $1^{\text {st }}$ division can re-appear TEE for improvement within six months from the date issue of final statement of marks/grades. Similarly the Master's degree programme learners can also reappear TEE who fall short of $2 \%$ marks to secure $55 \%$ marks.

\section{Alternative Assessment Methods:}

In distance education system the above three types of assessment are commonly used with objective, short-answer and long answer types questions. However, there are some other forms of assessment that can be used effectively in distance education. These are: peer assessment, projects, portfolio, viva-voce/oral examination, internship, and seminar presentation. Some of these other assessment methods used in IGNOU for overall assessment are discussed below.

\section{Peer Assessment:}

Peer assessment is an activity in which students judge the performance of their peers. This method of assessment is used to assess the work done by people of equal status. Peer assessment or peer review provides a structured learning process for students to critique and provide feedback to each other on their work. It is believed that in a professional context, the peer-group knows best about developments in a field, and is the best experts to judge a piece of work. It is highly useful to develop skills of assessment and judgment in a particular discipline. Besides, peer assessment is useful in developing critical understanding of the discipline/topic/subject, and promotes skills of group work. It is widely used in online group discussions in the form of peer rating of the postings and also in review of professional publications like books and journal articles.

\section{Project Assessment:}

Project-based assessment is an alternative to tests that allows students to engage with their learning in more concrete ways. Instead of merely studying theory, a hands-on project engages students to an in-depth exploration of a topic. One can use projects as part of the ongoing learning process. The use of project as assessment provides the learners with practical skills, and also abilities to communicate their work effectively. In IGNOU, a comprehensive project manual is given to the learners to clarify their doubts. The project manual explains the issues related to supervision, assessment procedures, length of the project, duration of work, referencing style etc. In some courses, oral examination/viva voce is used as additional assessment method to authenticate the work done by the distance learners in project. IGNOU is using this Project Assessment method in some programmes for overall assessment.

\section{Portfolio Assessment:}

Portfolio is a systematic record of student work that can exhibit a student's efforts, progress, and achievements in various areas of the curriculum over a period of time. Through portfolio, we can understand the willingness of a person to learn and his/her personal reflection in the process of learning and development. A portfolio assessment can be an examination of student-selected samples of work experiences and documents related to outcomes being assessed. It can address and support progress toward achieving academic goals, including student efficacy. The portfolio assessment tool is used in professional and vocational subjects such as fashion, art and management. However, portfolio is getting popular in other disciplines with the introduction of online portfolio systems. Portfolio assessment helps the learner to do self assessment, to be creative and independent.

\section{Oral Examination:}

Oral Examination is an interview or viva-voce conducted at the end of a project or at the end of an assessment process in order to know the language proficiency, knowledge, skills and abilities of a learner. Oral examinations can also be used in the form of group discussions. It is also possible with the use of online technology, particularly synchronous audio conferencing. IGNOU is conducting oral examinations for some practical/project based courses and the marks/grades secured are incorporated in overall assessment.

\section{Seminar Presentation:}


A seminar presentation is a short informal talk before a group delivering information or demonstrating something on a topic. It is an act of sharing ideas or discoveries in a way that gives seminar participants an opportunity for discussion. These presentations form a normal part of the teaching and learning process in undergraduate and postgraduate studies. In professional courses, learners are expected to be proficient in the art of presentations. When a student has done in-depth study and research in an area, his/her confidence is shown in the clarity of the presentation and the way he/she makes the presentation.

\section{Internship:}

An internship is a professional learning experience that offers meaningful, practical skills, workplace experience and greater knowledge of work related to a student's field of study or career interest. The internship is not normally done for the purpose of assessment but is usually done for giving actual work experience to the learner. In highly skill based courses, internship is used to give hands on experience to the learners to handle actual projects, machines, and tools to work and learn the tricks of the trade on the floor. Students are attached to supervisors/mentors who provide critical inputs and support to the learners to rectify their mistakes and learn. During internship, the learners are expected to prepare a report of their experience in the internship for assessment and supervisor provides confidential report to the institution on the work experience of the learner, which forms part of the total assessment. Internship component is there in MAPC and MSCDFSM programmes of IGNOU.

\section{Marking and Grading pattern of IGNOU}

In education, marking is the process of awarding a score to represent the level of learning achievement of a student. Marks are scores, mostly numerical, applied to individual tasks. Grading is the process of applying standardized measurements of varying levels of learning achievement. Grades can be assigned in letters or in numbers. Grades are commonly determined by adding up the raw data of marks or scores, and converting this to a band of achievement. Both marks and grades are symbolic representations that summaries the quality of student work and level of achievement. Marks and Grades are used to represent the level of learning a student has achieved. In distance education system, both marking and grading are used to report student performance. Though grading is the most favoured practice in world, many Indian educational institutions favour marking to avoid the problem of conversion of grades into marks particularly to facilitate mobility of distance learners to other institutions. We are familiar with the marking scheme that follows a 0-100 scale, and accordingly absolute scores are given to student performances in examination/test/ assignment within this scale. However, the scale in the grading pattern could be five points, seven points or nine points. IGNOU follows a five point grade system with the notional values given in Table-1(STRIDE, IGNOU, 2012).

Table 1:-

\begin{tabular}{|l|l|l|l|}
\hline Letter Grade & Quality Level & Point Grade & Point Grade Range \\
\hline A & Excellent & 5 & 4.5 and above \\
\hline B & Very Good & 4 & 3.5 but less than 4.5 \\
\hline C & Good & 3 & 2.5 but less than 3.5 \\
\hline D & Satisfactory & 2 & 1.5 but less than 2.5 \\
\hline E & Unsatisfactory & 1 & below 1.5 \\
\hline
\end{tabular}

In IGNOU, different programmes follow different schemes of marking and grading. In some programmes $35 \%$ is the pass mark, whereas in others $40 \%$ is the pass mark. For programmes that use grading system, C is pass grade in some, whereas $\mathrm{D}$ is pass grade for others. In some programmes average ' $\mathrm{C}$ ' in term-end examinations and assignment is pass grade, while in others learners have to secure ' $\mathrm{C}$ ' in both assignments and term-end examinations to pass. Though the evaluation in majority of the programmes is done as per the grading system along with the letter grades, the range of percentage equivalence marks are also given in the grade card, as mentioned in the table- 2 below: 
Table 2:-

\begin{tabular}{|l|l|l|l|l|l|}
\hline $\begin{array}{l}\text { Letter } \\
\text { Grade }\end{array}$ & Quality Level & $\begin{array}{l}\text { Point } \\
\text { Grade }\end{array}$ & Point Grade Range & $\begin{array}{l}\text { Percentage range } \\
\text { where minimum } \\
\text { qualifying score is } \\
\mathbf{3 5 \%}\end{array}$ & $\begin{array}{l}\text { Percentage range } \\
\text { where minimum } \\
\text { qualifying score is } \\
\mathbf{4 0 \%}\end{array}$ \\
\hline A & Excellent & 5 & 4.50 and above & $70 \%$ and above & $80 \%$ and above \\
\hline B & Very Good & 4 & 3.50 to 4.49 & $55 \%$ to $69.9 \%$ & $60 \%$ to $79.9 \%$ \\
\hline C & Good & 3 & 2.50 to 3.49 & $45 \%$ to $54.9 \%$ & $40 \%$ to $59.9 \%$ \\
\hline D & Satisfactory & 2 & 1.50 to 2.49 & $35 \%$ to $44.9 \%$ & $20 \%$ to $39.9 \%$ \\
\hline E & Unsatisfactory & 1 & 0 to 1.49 & Below $35 \%$ & Below $20 \%$ \\
\hline
\end{tabular}

But, the conventional institutions are still following the system of providing percentage mark which creates problem for a learner of IGNOU to move to the conventional system for higher study. In order to facilitate the learners, IGNOU has been using the following conversion formula from Grade Point Average (GPA) to Percentage (PC) equivalent by applying the method of at least square fit to obtain the best fit between two variable $\mathrm{X}$ and $\mathrm{Y}$.

$$
\begin{aligned}
& \mathrm{Y}=-62.5+99.167 \mathrm{X}-30 \mathrm{X}^{2}+3.333 \mathrm{X}^{3} \\
& \text { Where, } \\
& \mathrm{X}=\text { Cumulative Grade point Average (CGPA) } \\
& \mathrm{Y}=\text { Equivalent percentage in respect of above Grade Point }
\end{aligned}
$$

Example:

$$
\begin{aligned}
& \text { Let } \mathrm{X}=3.50 \text {, then } \\
& \qquad \begin{aligned}
\mathrm{Y} & =-62.5+99.167 \times 3.50-30 \times(3.50)^{2}+3.333 \times(3.50)^{3} \\
& =-62.5+347.0845-367.5+142.9024 \\
& =59.9869
\end{aligned}
\end{aligned}
$$

At the junction point of Grades and percentages, slight adjustment is made by rounding off to the next point. All other Grade Points are converted to the corresponding percentage in the similar fashion. In case of IGNOU BEd, with reference to the IGNOU notification date $18^{\text {th }}$ December 2012 (IGNOU News, 2012), course of 4 credits is equivalent to 100 marks. Accordingly, the maximum marks for the B.Ed programme of IGNOU up to the academic session 2000-2001 to 2008-2009, the maximum mark was 1100. Similarly, the maximum mark for BEd Programmes starting from the academic session 2009-2010 was 1300. Now, IGNOU has introduced new courses for BEd from 2016 and the learner has to complete total 72 credits for successful completion of BEd programme. Therefore, the equivalence maximum marks of IGNOU BEd from 2016 onwards will be 1800.

\section{Perception of learners on Assessment system of IGNOU:}

The feedbacks from different IGNOU learners admitted for different programmes under Regional Centre, Bhubaneswar are analyzed and their opinions on present academic assessment system are presented below.

1. Evaluation of assignment responses are not evaluated timely and evaluators are not putting proper tutor comments to encourage the distance learners.

2. Assignment responses are not returned to the learners in time and awards are not incorporated in the learner's grade card correctly.

3. Some learners are complaining that TEE answer sheets are not evaluated properly and thoroughly so that some good learners are securing very poor marks and bad learners are getting good marks.

4. Some learners are not getting examination centres in nearby region as per their choice.

5. The UFM cases are not solved in time and getting delayed so that learners are getting confused before the forthcoming TEE form fill up.

6. Re-evaluation charge of IGNOU is Rs.750/- per course which is very high.

7. Marksheet and provisional certificates are not reaching to the learner's address in time as the change of address is not properly updated in SED division.

8. As the convocation is done once in a year, one has to wait for one year to get the final degree certificate, but it would be better if the convocation is done twice in a year.

9. IGNOU question pattern in its examinations do not follow any regularity what we see in most of the Indian universities. So students sometimes find it difficult when they face examinations if they do not learn their course thoroughly.

10. All the evaluators do not have adequate knowledge in the subjects they do evaluate.

11. Assignment questions are very complex and contain subject matters only. 
12. Some learners feel that assignments should not be made compulsory as they do not have enough time to write assignments.

13. Some learners opined that IGNOU should allow submitting printed assignment responses without making compulsory for handwritten assignment responses.

14. Online assignment submission and evaluation facility should be introduced by IGNOU.

15. Constructive feedback is not given for all assignments

\section{Perception of assessors on academic assessment system of IGNOU:}

Views of different academic assessors working with IGNOU Regional Centre Bhubaneswar are analyzed and their perceptions are summarized in the following ways.

1. Most of the assessors of IGNOU are from conventional educational system but they are not oriented properly about IGNOU examination/evaluation pattern.

2. As there is no tracking system with IGNOU at present, sometimes evaluators are getting overloaded to evaluate excess responses of assignment or TEE answer sheets within a stipulated period.

3. Some of the learners are not collecting the assignment responses from the Study Centres after evaluation due to lack of awareness.

4. Some learners are not writing assignments in their own language with proper format.

5. Some learners are also copying assignment responses/project reports either from other learners or from readily available answers in market.

6. In TEE answer sheets and assignment responses, some learners are found to be copying from study materials.

\section{Recommendations/Suggestions:}

Following few recommendations/suggestions are proposed to make the academic assessment system of IGNOU more effective.

1. Since most of the assessors of IGNOU are from educational colleges/institutions, they should be oriented timely about the IGNOU examination/evaluation pattern.

2. IGNOU should follow a tracking mechanism for the evaluators for timely evaluation of the assignment responses as well as the answer sheets of TEE in order to declare the results in proper time.

3. IGNOU should introduce online tracking system for the evaluators so that the evaluators will not get excess answer sheets from many RECs at a time and evaluators can submit the answer sheets in time.

4. Answer sheets should be evaluated properly and thoroughly so that all learners secure proper marks/grades.

5. Qualitative assessment process should be implemented.

6. Proper monitoring on assessment should be adopted and examination centres should be monitored through technology based CCTV.

7. All certificates should be available online so that a learner can access and use his/her degrees anywhere.

8. Grade card in aggregate with grade and/or percentage of each course should be available online/offline at the end of each Term End Examination. This will be more useful to the learners who want to improve upon their final grade or percentage.

9. Evaluators should put proper tutor comments in assignment responses in order to encourage the distance learners.

10. Awareness among the learners should be created among the learners for collecting the assignments responses form the Study Centres after evaluation.

11. IGNOU should facilitate all learners to get their examination centres in their nearby region.

12. The UFM cases should be solved in time before the starting of forthcoming TEE form fill up.

13. The change of addresses updated in Student Registration Division (SRD) is not properly updated in SED. Therefore, IGNOU should maintain single database for all divisions so that all communications including marksheet and provisional certificates will reach the learners to their updated address in time.

14. A learner has to wait for one year to get the final degree certificate as the convocation is done once in a year, but it would be better if the convocation can be done twice in a year.

15. Suggested for fully online examination system. IGNOU should facilitate the learners to submit their responses online. The evaluators should have online access to the responses topic wise, region wise and send the scores directly to the Student Evaluation Division with the comments to the students through e-mail.

16. Most of the assessors have tendency to be lenient for distance learners which can be avoided by providing proper guidance and training on distance education set up.

17. In order to put accurate mark/grade, the assessors should not assess student's answer scripts/assignment responses quickly and unconsciously but the same may be done slowly and carefully. 
18. IGNOU should restrict to 20-25 assignments for each evaluator per week in order to maintain proper quality of assignment evaluation and there should be more number of academic counsellors to evaluate the assignment responses.

\section{Conclusions:-}

Academic assessment is the key of qualitative growth of distance education system. In this paper, an attempt has been made to study the details of learner's academic assessment process used by IGNOU. The concepts of assessment in distance education system with different types of commonly used assessment techniques in distance education are discussed. The five point grading system followed by IGNOU for its various programmes are analyzed. Though the evaluation in majority of the programmes is done as per the grading system along with the letter grades, the range of percentage equivalence marks are also discussed in details. Perceptions of learners/assessors on evaluation system of IGNOU are pointed. The above discussion leads us to conclude that:

1. In order to improve academic assessment system of IGNOU, regular orientation and training programmes with follow up feedback mechanism are necessary for academic assessors in order to make them understand and perform the roles expected of them with full satisfaction. Similarly awareness of learners into the distance learning process is very essential.

2. In order to get qualitative assessment system, technology based assessment system with monitoring mechanism should be developed and designed by the Schools, the Regional Centres and the Regional Evaluation Division.

3. Inadequate numbers of evaluators is partly to blame for the ineffectiveness of the process of academic assessment

4. As there is no tracking system with IGNOU at present, sometimes evaluators are getting overloaded to evaluate excess responses of assignment or TEE answer sheets within a stipulated period. Therefore, IGNOU should introduce online tracking system for the evaluators.

5. IGNOU should facilitate the learners to submit their responses online. The evaluators should have online access to the responses topic wise, region wise and send the scores directly to the Student Evaluation Division with the comments to the students through e-mail.

6. IGNOU should maintain single database for all divisions so that all communications including marksheet and provisional certificates will reach the learners to their updated address in time.

IGNOU has been recognized by various international organizations for its services throughout the world. However, more efforts for improvement of academic assessment system would further enhance the quality IGNOU programmes.

\section{References:}

1. AISHE Report (2018):

http://aishe.nic.in/aishe/viewDocument.action;jsessionid=19FA96098910ACCBDAA8623989E8684C?docume ntId $=245$

2. P. K. MEHTA and ANLIRAG SAXENA(2003):Emerging Trends in Student Assessment in ODLS, Indian Journal of Open Learnmg, 13 (2), 167- 179.

3. Moumita Das \& Chinmoy Kumar Ghosh(2013): Innovation in Open \& Distance Learning System:The IGNOU experience,Turkish Online Journal of Distance Education-TOJDE, 14(3), Article 12.

4. Travis.J(1996), Meaningful assessment, Clearing House, 69(5), 308-312.

5. S.V.S. Choudhary \& Niradhar Dey(2013):Assessment in ODL System: A challenge, Open Praxis, 5(3), 207216.

6. Pravat Ku. Jena(2018): Academic Counselling Services in IGNOU, Int. J. Adv. Res. 6(4), 441-448.

7. STRIDE, IGNOU (2012): Learner support systems and services.MDE-413: Block-4.

8. IGNOU News (2012):

http://ignou.ac.in/ignou/bulletinboard/news/latest/detail/Maximum_marks_for_B_Ed_programme-428 